\title{
Clero e Independencia. Reflexiones latinoamericanas
}

\section{Carolina Abadía Quintero}

\begin{abstract}
Albornoz, Oswaldo. (2009). Oposición del clero a la Independencia. Quito: Colección Bicentenaria. 166 pags.

La celebración de los bicentenarios de Independencia congrega por estos días a la mayoría de hispanoamericanos. En los festejos, sin lugar a dudas participan los académicos e intelectuales de cada una de las naciones de nuestro continente, quienes a partir de la realización de encuentros académicos y con la publicación de importantes obras de análisis y reflexión, intentan estudiar los procesos de Independencia bajo otra óptica, brindando nuevas interpretaciones sobre tan importantes proceso.
\end{abstract}

Nuevos actores y nuevas dinámicas por tanto están siendo visibilizados. Nuevos puntos de vista nos han demostrado que los relatos construidos con anterioridad carecían de ciertos datos y fuentes que enriquecen el estudio de nuestras emancipaciones. Sin embargo, aún faltan mayores análisis y perspectivas de trabajo, pues siguen sin estudiar agentes sociales y dinámicas determinantes en los procesos de Independencia.

Para ejemplificar tal situación, vale la pena no más mencionar la participación de los miembros del clero, pues por lo menos en Colombia, a excepción de algunos trabajos de Fernán González y Juan Manuel Pacheco, la reflexión tanto a nivel nacional como regional, en torno a cuál fue el rol asumido por los miembros del clero es prácticamente nula.

Ante tal situación aparece el libro Oposición del clero a la Independencia, del historiador ecuatoriano Oswaldo Albornoz, obra nuevamente editada en el marco de la celebración del Bicentenario en la República del Ecuador. Su autor, ya fallecido, posee una importante y consagrada trayectoria académica en el vecino país. Sus trabajos históricos no solo han estado centrados en el rol del clero en ciertos procesos de la historia ecuatoriana, sino que a la vez se dedicó a estudiar otro tipo de sectores, indígenas y obreros, y personajes determinantes, Simón Bolívar, Eloy Alfaro, Eugenio Espejo, en la historia ecuatoriana.

La presente obra, constituida por cuatro capítulos, presenta al lector distintos hechos de las Independencia hispanoamericana, que llevan a Albornoz a afirmar que el clero fue esencialmente agente opositor de los procesos de Independencia y abiertamente favorable a la causa realista. El autor recoge importantes datos e intenta construir una obra que abarca en su totalidad al inmenso continente

\footnotetext{
* Licenciada en Historia, Universidad del Valle. Aspirante a Maestría en Historia de la Universidad del Valle. Docente de la Universidad del Valle, sede Buga. Asistente de Investigación del proyecto "Diócesis de Cali: un siglo de historia regional". Integrante de la Asociación Centro de Estudios Regionales Región. E-mail: cabaquin@gmail.com
} 
latinoamericano, recordando las acciones anti emancipatorias de muchos renombrados miembros de la clerecía.

En el primer capítulo, Albornoz se dedica a señalar cómo han sido muchos los historiadores que erróneamente han creído que en su mayoría fueron muchos los miembros de la Iglesia, que apoyaron y fomentaron la emancipación en nuestro continente: "el cuento del apoyo clerical a nuestra liberación de España no es sino la creación de historiadores reaccionarios interesados en prestigiar a la Iglesia..." (Albornoz, 2009, p. 30). Contrariando tal posición, Albornoz inicia su recorrido historiográfico, en las décadas finales del siglo XVIII, describiendo como los levantamientos de Tupac Amarú y de los comuneros, tuvieron en los miembros del clero, a sus principales enemigos.

En el siguiente capítulo titulado "De las causas finales", el autor se dedica a explicar las razones políticas, económicas y culturales por las cuales la Iglesia católica americana no apoya los procesos de emancipación en el continente, entre las que se encuentran: 1) su obediencia al Papa y a Roma, y hay que tener en cuenta que no es sino hasta mediados del siglo XIX que la Santa Sede acepta los nuevos gobiernos en América, 2) el temor a que con la independencia una ola de irreligiosidad se extienda por el continente; y 3) la amenaza que se cierne frente a la estabilidad interna de la clerecía, al enfrentar a distintos sectores del clero que se declaraban a favor o en contra de la emancipación de España.

En el tercer capítulo, "El testimonio de los hechos", Albornoz realiza un minucioso estudio del accionar de cada uno de los arzobispos y obispos en el marco de las luchas de Independencia, en toda América, desde el Virreinato de la Nueva España hasta la Capitanía General de Chile, ofreciendo valiosos datos sobre procesos y personajes determinantes en esos primeros años del siglo XIX. En este capítulo sin lugar a dudas, el autor comprueba entonces su tesis inicial, mostrando cómo en suma, los destacados miembros de la alta jerarquía católica fueron seguidores de la causa del rey Fernando VII. Sin embargo, con el cambio de marea, y la ascensión de los patriotas a lo largo y ancho del continente, fueron muchos los miembros clericales que cambiaron de bando y de lealtades.

Finalmente, en "Ayer y Hoy", último capítulo de la presente obra, el autor presenta una reflexión en la que propone que la Iglesia y en general sus integrantes son ampliamente opositores de las justas causas políticas, económicas, culturales y sociales del continente americano, situación que se presenta por sus múltiples intereses particulares como institución transnacional.

Si bien el presente libro se destaca por realizar un importante análisis de la participación y posición de la clerecía frente a los hechos de la Independencia, vale la pena señalar algunos puntos de debate. En primera instancia, el título da a entender al lector que fue todo el clero, (bajo, alto, secular, laico), el que se opuso a las gestas emancipatorias americanas. Sin embargo, el autor a lo largo del libro deja entrever que su análisis está centrado en la crítica a las altas jerarquías obispos y arzobispos-, pues destaca incluso el importante papel asumido por 
integrantes del clero bajo y de ciertas órdenes religiosas no sólo en la consecución de la independencia sino en la construcción de los estados republicanos. El autor por tanto no es claro al delimitar el grupo clerical al que estudia, totalizando entonces el accionar eclesiástico.

Hay que entrar a cuestionar a la vez el tono interpretativo utilizado por Albornoz en su obra, el cual resulta en extremo pasional y en algunos acápites, peyorativo, frente a ciertas acciones y posiciones clericales. Pareciera que el autor en vez de asumir una actitud reflexiva, muy propia del oficio del historiador, fuera juez y parte, pues las acusaciones contra la Iglesia y su discurrir en la historia de América, son constantes al realizar la lectura del texto.

En suma, si bien el lenguaje no es cauto y existen ciertas inconsistencias frente a los actores y las acciones de la clerecía en la historia de la Independencia, esta obra resulta importante en la medida en que alimenta con su reflexión, el estudio de tan significativa gesta histórica de nuestras naciones latinoamericanas. 